\title{
PHASE BEHAVIOR OF LIGHT GASES IN HYDROCARBON AND AQUEOUS SOLVENTS
}

\author{
Report for the Period \\ from March 31, 1998 to August 31, 1998
}

\author{
K. A. M. Gasem \\ R. L. Robinson, Jr. \\ (Principal Investigators) \\ W. Gao \\ K. H. Row
}

Oklahoma State University

School of Chemical Engineering

Stillwater, Oklahoma 74078-0537

PREPARED FOR THE UNITED STATES

DEPARTMENT OF ENERGY 


\section{DISCLAIMER}

This report was prepared as an account of work sponsored by an agency of the United States Government. Neither the United States Government nor any agency thereof, nor any of their employees, makes any warranty, express or implied, or assumes any legal liability or responsibility for the accuracy, completeness, or usefulness of any information, apparatus, product, or process disclosed or represents that its use would not infringe privately owned rights. Reference herein to any specific commercial product, process, or service by trade name, trademark, manufacturer, or otherwise does not necessarily constitute or imply its endorsement, recommendation, or favoring by the United States Government or any agency thereof. The views and opinions of authors expressed herein do not necessarily state or reflect those of the United States Government or any agency thereof. 


\title{
PHASE BEHAVIOR OF LIGHT GASES IN HYDROCARBON AND AQUEOUS SOLVENTS
}

\begin{abstract}
Under previous support from the Department of Energy, an experimental facility has been established and operated to measure valuable vapor-liquid equilibrium data for systems of interest in the production and processing of coal fluids. To facilitate the development and testing of models for prediction of the phase behavior for such systems, we have acquired substantial amounts of data on the equilibrium phase compositions for binary mixtures of heavy hydrocarbon solvents with a variety of supercritical solutes, including hydrogen, methane, ethane, carbon monoxide, and carbon dioxide.
\end{abstract}

The present project focuses on measuring the phase behavior of light gases and water in Fischer-Tropsch (F-T) type solvents at conditions encountered in indirect liquefaction processes and evaluating and developing theoretically-based correlating frameworks to predict the phase behavior of such systems. Specific goals of the proposed work include (a) developing a state-ofthe-art experimental facility to permit highly accurate measurements of equilibrium phase compositions (solubilities) of challenging F-T systems, (b) measuring these properties for systematically-selected binary, ternary and molten $F-T$ wax mixtures to provide critically needed input data for correlation development, (c) developing and testing models suitable for describing the phase behavior of such mixtures, and (d) presenting the modeling results in generalized, practical formats suitable for use in process engineering calculations.

During the present period, the Park-Gasem-Robinson (PGR) equation of state (EOS) has been modified to improve its volumetric and equilibrium predictions. Specifically, the attractive term of the PGR equation was modified to enhance the flexibility of the model, and a new expression was developed for the temperature dependence of the attractive term in this segmentsegment interaction model.

The predictive capability of the modified PGR EOS for vapor pressure, and saturated liquid and vapor densities was evaluated for selected normal paraffins, normal alkenes, cycloparaffins, light aromatics, argon, carbon dioxide and water. The generalized EOS constants and substance-specific characteristic parameters in the modified PGR EOS were obtained from the pure component vapor pressures, and saturated liquid and vapor molar volumes. The calculated phase properties were compared to those of the Peng-Robinson (PR), the simplified-perturbedhard-chain theory (SPHCT) and the original PGR equations. Generally, the performance of the proposed EOS was better than the PR, SPHCT and original PGR equations in predicting the pure fluid properties (\%AAD of 1.3, 2.8 and 3.7 for vapor pressure, saturated liquid and vapor densities, respectively).

A manuscript we have prepared for publication is attached in lieu of detailed technical information. 


\section{TABLE OF CONTENTS}

Section $\quad \underline{\text { Page }}$

Executive Summary 1

$\begin{array}{ll}\text { Manuscript } & 2\end{array}$ 
PROJECT TITLE: "Phase Behavior of Light Gases in Hydrocarbon and Aqueous Solvents"

PRINCIPAL INVESTIGATORS: K. A. M. Gasem

R. L. Robinson, Jr.

AFFILIATION: School of Chemical Engineering

Oklahoma State University

Stillwater, OK 74078

(405) 744-5280

PROJECT PERIOD: March 31, 1998 to August 31, 1998

\section{EXECUTIVE SUMMARY}

The Park-Gasem-Robinson (PGR) equation of state (EOS) has been modified to improve its volumetric and equilibrium predictions. Specifically, the attractive term of the PGR equation was modified to enhance the flexibility of the model, and a new expression was developed for the temperature dependence of the attractive term in this segment-segment interaction model.

The predictive capability of the modified PGR EOS for vapor pressure, and saturated liquid and vapor densities was evaluated for selected normal paraffins, normal alkenes, cycloparaffins, light aromatics, argon, carbon dioxide and water. The generalized EOS constants and substance-specific characteristic parameters in the modified PGR EOS were obtained from the pure component vapor pressures, and saturated liquid and vapor molar volumes. The calculated phase properties were compared to those of the Peng-Robinson (PR), the simplified-perturbedhard-chain theory (SPHCT) and the original PGR equations. Generally, the performance of the proposed EOS was better than the PR, SPHCT and original PGR equations in predicting the pure fluid properties (\%AAD of 1.3, 2.8 and 3.7 for vapor pressure, saturated liquid and vapor densities, respectively). 


\title{
THE MODIFIED PGR EQUATION OF STATE:
} PURE-FLUID PREDICTIONS

\author{
K. H. Row
}

R. L. Robinson, Jr.

K. A. M. Gasem

School of Chemical Engineering

Oklahoma State University

423 Engineering North

Stillwater, OK 74078 


\begin{abstract}
The Park-Gasem-Robinson (PGR) equation of state (EOS) has been modified to improve its volumetric and equilibrium predictions. Specifically, the attractive term of the PGR equation was modified to enhance the flexibility of the model, and a new expression was developed for the temperature dependence of the attractive term in this segment-segment interaction model.

The predictive capability of the modified PGR EOS for vapor pressure, and saturated liquid and vapor densities was evaluated for selected normal paraffins, normal alkenes, cycloparaffins, light aromatics, argon, carbon dioxide and water. The generalized EOS constants and substance-specific characteristic parameters in the modified PGR EOS were obtained from the pure component vapor pressures, and saturated liquid and vapor molar volumes. The calculated phase properties were compared to those of the Peng-Robinson (PR), the simplified-perturbedhard-chain theory (SPHCT) and the original PGR equations. Generally, the performance of the proposed EOS was better than the PR, SPHCT and original PGR equations in predicting the pure fluid properties (\%AAD of 1.3, 2.8 and 3.7 for vapor pressure, saturated liquid and vapor densities, respectively).
\end{abstract}




\section{INTRODUCTION}

Equations of state (EOSs) continue to be the models of choice in numerous chemical engineering applications, particularly when dealing with multiphase equilibria calculations. van der Waals EOS has been a basis for several EOSs, which provide both volumetric and equilibrium properties. Among these EOSs, the SRK [25] and PR [20] equations are widely used in industry. Although these equations are essentially empirical, their predictive capabilities for the equilibrium properties of mixtures containing simple and normal fluids are good. However, since both equations are based on molecule-molecule interactions, their application to asymmetric mixtures has not been as favorable [13, 24].

Continued interest in asymmetric mixtures has generated new requirements for thermodynamic models for systems containing small molecules and heavy solvents. Also the development of fast computers makes it possible to perform Monte Carlo simulations and molecular dynamics simulations to delineate molecular interactions. These simulation results have stimulated the development of theoretically-based EOSs. The perturbed-hard-chain theory equation of state (PHCT) $[4,10]$ has been successful in representing the phase behavior of chain molecules and asymmetric mixtures. The attractive term of this equation is based on the molecular simulation results of Alder et al. [1], in which molecules are assigned square-well potential interactions.

A simplified form of the PHCT equation (SPHCT equation) was proposed by Donohue and coworkers [15]. They replaced the attraction term of the PHCT equation with the local composition model of Lee et al. [16]. This equation has a comparable predictive capability to the SRK and PR equations in representing the phase behavior of simple molecules, and has a better capability for handling some asymmetric mixtures [13, 24]. Although this equation has the advantages of a segment-interaction model, it suffers from several shortcomings, as we have described previously. Thus, a modification to improve the SPHCT EOS predictions was undertaken [23]. The Modified SPHCT EOS is better than the original SPHCT EOS in representing equilibrium and volumetric properties for a variety of pure fluids; however, the mixture property predictions remain comparable to the original SPHCT model. 
Recently, Park [19] proposed a new EOS to benefit from insights gained in modifying the SPHCT equation. The PGR equation of state was derived from the generalized van der Waals partition function for chain-like molecules proposed by Donohue and Prausnitz [10]. The equation has a simple repulsive term proposed by Elliott and coworkers [11] and an augmented generalized cubic equation attractive term. A correction term was added to the attractive term of the generalized cubic equation to improve its under-predicted fluid compressibility factors. The temperature dependence of the PGR equation is based on an augmented square-well potential for segment interactions.

In this work, the PGR EOS is modified to obtain more accurate volumetric, equilibrium and calorimetric predictions.

\section{MODIFICATION OF THE PGR EQUATION OF STATE}

The PGR is a segment-segment molecular interaction EOS. The van der Waals partition function for chain-like molecules of Donohue and Prausnitz [10] is used in developing the equation. Each molecular segment is considered as a hard sphere with its free volume adopted from the expression given by Elliott and coworkers [11]. A square-well potential is used to represent the segment-segment attraction energy. The density dependence of the radial distribution function of the PGR equation leads to the attractive term of an augmented generalized cubic equation of state. The original PGR EOS may be written as

$$
\begin{aligned}
& \mathrm{Z}=1+\mathrm{c}\left(\frac{\beta_{1} \eta}{1-\beta_{2} \eta}-\frac{\alpha \mathrm{Yv}_{\mathrm{r}}}{\mathrm{v}_{\mathrm{r}}^{2}+\mathrm{uv}_{\mathrm{r}}+\mathrm{w}}-\frac{\mathrm{Q} \alpha \mathrm{Y}}{\mathrm{v}_{\mathrm{r}}+1}\right) \\
& \alpha=\alpha_{0} \mathrm{~h}(\mathrm{~T}) \\
& \mathrm{Y}=\exp \left(\frac{1}{\widetilde{\mathrm{T}}}\right)-1 \\
& \mathrm{~h}(\mathrm{~T})=1+\kappa_{1} \widetilde{\mathrm{T}}^{1 / 2}+\kappa_{2} \widetilde{\mathrm{T}}+\kappa_{3} \widetilde{\mathrm{T}}^{2}+\kappa_{4} \widetilde{\mathrm{T}}^{-1} \\
& \widetilde{\mathrm{T}}=\frac{\mathrm{T}}{\mathrm{T}^{*}}, \quad \mathrm{v}_{\mathrm{r}}=\frac{\mathrm{v}}{\mathrm{v}^{*}}
\end{aligned}
$$


where $\alpha_{0}, \beta_{1}, \beta_{2}, \kappa_{1}, \kappa_{2}, \kappa_{3}$ and $\kappa_{4}$ are the PGR EOS constants, and $c$ is the degree of freedom parameter. The repulsive and attractive terms of the equation expressed as compressibilities are

$$
\begin{aligned}
& Z^{\text {rep }}=1+\frac{\beta_{1} \eta}{1-\beta_{2} \eta} \\
& Z^{\text {att }}=\left(-\frac{\alpha \mathrm{Yv}_{\mathrm{r}}}{\mathrm{v}_{\mathrm{r}}^{2}+\mathrm{uv}_{\mathrm{r}}+\mathrm{w}}-\frac{\mathrm{Q} \alpha \mathrm{Y}}{\mathrm{v}_{\mathrm{r}}+1}\right)
\end{aligned}
$$

\section{The Repulsive Term}

The repulsive term of an EOS is often used to describe hard-sphere, hard-disc, or hardchain interactions without attraction energy between molecules. Monte Carlo or molecular dynamic simulation results are available in the literature for the repulsive contribution to the fluid compressibility for different densities [9, 12]. Among the equations of state for hard-spheres, Carnahan and Starling [6] provided one of the better known and more accurate expressions. Their expression is a simple correlation of the virial type analytical derivation for the hard-sphere compressibility factor [21].

$$
\mathrm{Z}^{\mathrm{rep}}=\frac{1+\eta+\eta^{2}-\eta^{3}}{(1-\eta)^{3}}
$$

where $\eta=\frac{1}{6}(\pi \sqrt{2})\left(\frac{\mathrm{v}^{*}}{\mathrm{v}}\right)$ and $\mathrm{v}^{*}$ is molar close packed volume for hard spheres. Several equations of state with the Carnahan and Starling repulsive term have been proposed in the literature $[8,17$, 18]. In general, these equations showed better or comparable performance to the PR and SRK equations in calculating fluid phase equilibrium properties of simple mixtures.

To simplify the form of the EOS, Elliott and coworkers [11] proposed an empirical expression for hard spheres given in Equation (5). We have adopted the Elliott expression although it is not as accurate in reproducing the molecular dynamics repulsive compressibilities of Erpenbeck and Wood [12]. 


\section{Modification of the Attractive Term}

The density dependence of the radial distribution function of the PGR equation leads to the attractive term of an augmented generalized cubic equation of state. As such the attractive term of this equation, similar to other EOSs, contains several assumptions, which simplify its temperature and density dependence $[5,7,13,24]$. In this study, we have sought a greater flexibility in the structural and temperature dependence of the attractive term.

The attractive term of the generalized cubic EOS such as SRK equation under-predicts compressibility factors compared to molecular simulation results [2, 11]. Accordingly, an additional term was proposed to eliminate one of the deficiencies of the cubic EOS attractive term. The two attractive terms are

$$
\begin{aligned}
& \mathrm{Z}_{\mathrm{att}}^{\mathrm{I}}=-\frac{\alpha \mathrm{Yv}_{\mathrm{r}}}{\mathrm{v}_{\mathrm{r}}^{2}+u \mathrm{v}_{\mathrm{r}}+\mathrm{w}} \\
& \mathrm{Z}_{\mathrm{att}}^{\mathrm{II}}=-\frac{\mathrm{Q} \alpha \mathrm{Y}}{\mathrm{v}_{\mathrm{r}}+1}
\end{aligned}
$$

In this study, a more general expression is suggested for the attractive term, which gives the equation added flexibility when applied to chain-like molecules

$$
\mathrm{Z}_{\mathrm{att}}^{\mathrm{II}}=-\frac{\mathrm{Q}_{1} \alpha \mathrm{Y}}{\mathrm{v}_{\mathrm{r}}+\mathrm{Q}_{2}}
$$

where $\mathrm{Q}, \mathrm{Q}_{1}$, and $\mathrm{Q}_{2}$ are all equation constants. In addition, the high sensitivity of the calculated properties to $\mathrm{T}^{*}$, as discussed by Shaver and coworkers [24], suggests that improvement in EOS predictions can be achieved by modifying the temperature dependence of the attractive term. A modified form for the radial distribution function of Equations (5) and (6) is

$$
\alpha Y=Z_{M} \alpha\left[\exp \left(F_{t}\right)-1\right]
$$

Where

$$
\alpha=1+\kappa_{1} \widetilde{\mathrm{T}}^{1 / 2}+\kappa_{2} \tilde{\mathrm{T}}+\kappa_{3} \widetilde{\mathrm{T}}^{2}+\kappa_{4} \widetilde{\mathrm{T}}^{-1}
$$




$$
\mathrm{F}_{\mathrm{t}}=\omega_{1}\left(\frac{1}{2 \tilde{\mathrm{T}}}\right)^{1 / 2}+\omega_{2}\left(\frac{1}{2 \tilde{\mathrm{T}}}\right)+\omega_{3}\left(\frac{1}{2 \tilde{\mathrm{T}}}\right)^{3 / 2}+\omega_{4}\left(\frac{1}{2 \tilde{\mathrm{T}}}\right)^{2}
$$

and $\mathrm{Z}_{\mathrm{M}}, \kappa_{1}, \kappa_{2}, \kappa_{3}, \kappa_{4}, \omega_{1}, \omega_{2}, \omega_{3}$, and $\omega_{4}$ are constants.

Table I presents a summary of results for several cases we have studied to identify a more accurate EOS. Using the Elliott repulsive model and the $F_{t}$ function above provides the best results (average absolute \% deviation of 1.0). Using $\alpha$ in addition to $F_{t}$ does not provide any improvement in vapor pressure predictions over the use of $F_{t}$ alone. Therefore, the present work is restricted to the use of only $F_{t}$.

By combining Equation (6), (8) and (10), the final form of the modified PGR EOS can be written as

$$
\mathrm{Z}=1+\mathrm{c}\left(\frac{\beta_{1} \tau}{\mathrm{v}_{\mathrm{r}}-\beta_{2} \tau}-\frac{\alpha \mathrm{Yv}_{\mathrm{r}}}{\mathrm{v}_{\mathrm{r}}^{2}+\mathrm{uv} \mathrm{v}_{\mathrm{r}}+\mathrm{w}}-\frac{\mathrm{Q}_{1} \alpha \mathrm{Y}}{\mathrm{v}_{\mathrm{r}}+\mathrm{Q}_{2}}\right)
$$

where $\mathrm{Y}$ and $\alpha$ are defined in Equations (11)-(13).

\section{Characteristic of the Modified PGR EOS}

The limiting behavior of this equation follows that of the other EOSs. As the molar volume approaches infinity at any temperature, the repulsive term of the equation becomes unity, and the attractive term becomes zero. Similarly, the EOS can be simplified to the ideal gas law as the system molar volume approaches infinity. At the highly compressed state, the molar volume can be calculated from the denominator of the repulsive term

$$
\mathrm{v}_{\min }=\beta_{1} \tau \mathrm{V}^{*}
$$

This molar volume of Equation (15) is the smallest possible molar volume. To find the liquid root, the initial guess for $\mathrm{Z}$ can be obtained from this molar volume

$$
\mathrm{Z}_{\min }=\frac{\beta_{1} \tau \mathrm{pv}^{*}}{\mathrm{RT}}
$$


As the temperature approaches infinity, the attractive term becomes negligible because ( $\alpha$ $\mathrm{Y})$ in the attractive term converges to zero, as shown in Figure 1. Moreover, when the molecular size (characteristic volume, $v^{*}$ ) is zero and the temperature goes to infinity, the equation also satisfies the ideal gas law.

The effect of introducing the modified function of $(\alpha Y)$ with $F_{t}$ on the attractive term can be seen in Figure 1. The original and the modified PGR equation show similar behaviors. However, the temperature derivative of $(\alpha Y)$ of the modified PGR equation is different near the break point where the reduced temperature value is 0.4 . The stability of this derivative plays an important role in calorimetric property calculations. Below this temperature the values of $(\alpha \mathrm{Y})$ are less steep than those of the original PGR equation. In Figure 2, the values of $(\alpha Y)$ from the original and modified PGR EOSs are shown relative to the values obtained from individual regressions of experimental data for methane. The values of ( $\alpha Y)$ obtained from the original PGR equation show greater deviation from the regressed values than those obtained using the modified PGR equation.

The sensitivity of calculated properties (vapor pressures and saturated liquid and vapor densities) to each of the three EOS parameters $\left(T^{*}, v^{*}, c\right)$ was determined from the triple point to the critical point for methane. The parameter sensitivity was defined as

$$
\frac{\mathrm{A}}{\mathrm{C}}\left(\frac{\partial \mathrm{C}}{\partial \mathrm{A}}\right)
$$

where $\mathrm{C}$ is the calculated property (vapor pressure and vapor and liquid density) and $\mathrm{A}$ is one of the equation parameters. The parameter sensitivity may be viewed as the percentage change in the calculated property, $\mathrm{C}$, caused by a $1 \%$ change in the equation parameter, $\mathrm{A}$.

Figures 3 through 5 show the sensitivity of calculated vapor pressure saturated liquid and saturated vapor densities, respectively. These figures show that the effect of variation in $v^{*}$ is nearly constant over the entire temperature range for all calculations. In addition, the vapor pressure is least sensitive to the parameter $v^{*}$, however, both vapor pressure and liquid density show significant variations with temperature for a given change in $\mathrm{T}^{*}$. This temperature dependence may indicate some remaining deficiency in the attractive term. The effects of $\mathrm{T}^{*}$ and $\mathrm{c}$ 
on vapor pressure and vapor density calculations are similar in trend and both have greater impact at low temperatures.

\section{THE MODIFIED PGR EOS}

The pressure explicit form of the modified PGR EOS given earlier may be written as

$$
\frac{\mathrm{pv}}{\mathrm{RT}}=1+\mathrm{c}\left(\frac{\beta_{1} \tau}{\mathrm{v}_{\mathrm{r}}-\beta_{2} \tau}-\frac{\mathrm{Z}_{\mathrm{M}} \mathrm{Yv}_{\mathrm{r}}}{\mathrm{v}_{\mathrm{r}}^{2}+\mathrm{uv}_{\mathrm{r}}+\mathrm{w}}-\frac{\mathrm{Q}_{1} \mathrm{Z}_{\mathrm{M}} \mathrm{Y}}{\mathrm{v}_{\mathrm{r}}+\mathrm{Q}_{2}}\right)
$$

where

$$
\begin{aligned}
& Y=\exp \left(F_{t}\right)-1 \\
& F_{t}=\omega_{1}\left(\frac{1}{2 \widetilde{T}}\right)^{1 / 2}+\omega_{2}\left(\frac{1}{2 \widetilde{T}}\right)+\omega_{3}\left(\frac{1}{2 \widetilde{T}}\right)^{3 / 2}+\omega_{4}\left(\frac{1}{2 \widetilde{T}}\right)^{2}
\end{aligned}
$$

The universal constants in this equation are shown in Table II. These EOS constants, including $\mathrm{u}$, $\mathrm{w}, \mathrm{Z}_{\mathrm{M}}, \mathrm{Q}_{1}, \mathrm{Q}_{2}$ and $\omega_{1}-\omega_{4}$ were regressed from pure fluid experimental data.

The modified EOS shown in the Equation (18) is fifth order in volume (or in compressibility factor). This equation can be expanded in terms of the compressibility factor, Z, as

$$
\mathrm{Z}^{5}+\mathrm{AZ} \mathrm{Z}^{4}+\mathrm{BZ}+\mathrm{CZ} \mathrm{Z}^{2}+\mathrm{DZ}+\mathrm{E}=0
$$

A, B, C, D and E are constants for a given temperature and pressure. This expanded form of the EOS (Equation (21)) and definitions for the coefficients are presented elsewhere [27]. Equation (21) is solved to identify liquid and vapor roots of $\mathrm{Z}$.

Fugacity coefficients are required in multi-phase equilibrium calculations. The fugacity coefficient of a pure fluid for the modified PGR EOS is 


$$
\begin{aligned}
\ln \phi & =-\mathrm{c} \frac{\beta_{1}}{\beta_{2}} \ln \frac{\mathrm{v}_{\mathrm{r}}-\beta_{2} \tau}{\mathrm{v}_{\mathrm{r}}} \\
& +\mathrm{cZ} \mathrm{M}_{\mathrm{M}} \mathrm{Y}\left[\frac{2}{\sqrt{4 \mathrm{w}-\mathrm{u}^{2}}}\left(\tan ^{-1} \frac{2 \mathrm{v}_{\mathrm{r}}+\mathrm{u}}{\sqrt{4 \mathrm{w}-\mathrm{u}^{2}}}-\frac{\pi}{2}\right)-\frac{\mathrm{Q}_{1}}{\mathrm{Q}_{2}} \ln \frac{\mathrm{v}_{\mathrm{r}}+\mathrm{Q}_{2}}{\mathrm{v}_{\mathrm{r}}}\right] \\
& +\frac{\mathrm{c} \beta_{1} \tau}{\mathrm{v}_{\mathrm{r}}-\beta_{2} \tau}-\frac{\mathrm{cZ} \mathrm{Y}_{\mathrm{r}}}{\mathrm{v}_{\mathrm{r}}^{2}+\mathrm{uv} \mathrm{v}_{\mathrm{r}}+\mathrm{w}}-\frac{\mathrm{cZ} \mathrm{M} \mathrm{Q}_{1}}{\mathrm{v}_{\mathrm{r}}+\mathrm{Q}_{2}}
\end{aligned}
$$

Detailed derivation of the above expression is given elsewhere [27].

\section{METHODS}

The modified PGR EOS proposed in this work has a set of universal constants for all compounds $\left(\mathrm{u}, \mathrm{w}, \mathrm{Q}_{1}, \mathrm{Q}_{2}\right.$, and $\left.\omega_{1}-\omega_{4}\right)$ and substance-specific pure component parameters $\left(\mathrm{T}^{*}\right.$, $\mathrm{v}^{*}$ and $\left.\mathrm{c}\right)$. Experimental vapor pressure data, along with liquid and vapor phase densities, at different temperatures were used to evaluate the universal constants and component parameters. The various data sets used in this work contain T-p- $\rho^{\mathrm{L}}-\rho^{\mathrm{v}}, \mathrm{T}-\mathrm{p}-\rho^{\mathrm{L}}, \mathrm{T}-\mathrm{p}$, or T- $\rho^{\mathrm{L}}$, as shown in the next section. The parameters for the original form of the PGR EOS $\left(\mathrm{T}^{*}, \mathrm{v}^{*}\right.$, and $\left.\mathrm{c}\right)$ were regressed to minimize the following objective function for both vapor pressures and phase densities

$$
\mathrm{SS}=\sum_{\mathrm{i}=1}^{\mathrm{N}}\left(\left(\frac{\mathrm{p}_{\text {exp }}-\mathrm{p}_{\text {calc }}}{\mathrm{p}_{\exp }}\right)_{\mathrm{i}}^{2}+\left(\frac{\rho_{\text {exp }}^{\mathrm{L}}-\rho_{\text {calc }}^{\mathrm{L}}}{\rho_{\exp }^{\mathrm{L}}}\right)_{i}^{2}+\left(\frac{\rho_{\exp }^{\mathrm{V}}-\rho_{\text {calc }}^{\mathrm{V}}}{\rho_{\exp }^{\mathrm{V}}}\right)_{\mathrm{i}}^{2}\right)
$$

The form of this objective function can be changed according to the availability of the information in the database. For the compounds with no available vapor densities, the three equation parameters were fit only to vapor pressures and liquid densities. When phase density data were not available, the last two terms of Equation (23) were omitted from the objective function and the three equation parameters were fit only to vapor pressures. The calculated values of vapor pressure and phase densities in the objective function were obtained using the EOS.

Multiple nonlinear regressions were used to regress the constants and the pure-component parameters $\left(\mathrm{T}^{*}, \mathrm{v}^{*}\right.$ and $\left.\mathrm{c}\right)$ in the equation. The constants in the equation $\left(\mathrm{u}, \mathrm{w}, \mathrm{Z}_{\mathrm{M}}, \mathrm{Q}_{1}, \mathrm{Q}_{2}\right.$ and 
$\left.\omega_{1}-\omega_{4}\right)$ were obtained mainly with the methane, ethane, propane, and butane saturation data. More information on the equilibrium calculation method and the regression technique used in this work is given by Gasem [14].

In calculating vapor pressures and saturated phase densities, a reliable solution algorithm is essential in determining the compressibility factors for the EOS. As mentioned in the previous section, both the original and modified PGR EOSs are fifth order in terms of the compressibility factor. To solve this equation efficiently, an initializing routine was implemented. This equationsolver algorithm, which is similar to Park's [19] approach, is as follows. First, the lower limit value of the compressibility factor in Equation (15) was taken as the initial value of compressibility factor, $\mathrm{Z}^{\mathrm{L}}$, for a liquid phase. The right-hand side of Equation (21) was calculated, starting with this initial value until its sign changed from negative to positive upon increasing $\mathrm{Z}^{\mathrm{L}}$ in $2 \%$ increments. When the change of sign occurred, the $\mathrm{Z}^{\mathrm{L}}$ value becomes a new initial value, and the simple Newton-Raphson Method was then used to locate the correct root. The initial value of the compressibility factor, $Z^{v}$, for a vapor phase was set to three. This value was decreased by $2 \%$ until the sign of the right hand side of Equation (21) changed from positive to negative. Then, the same Newton-Raphson Method was applied with the updated $\mathrm{Z}^{\mathrm{v}}$ as an initial guess. When the relative change of compressibility factor with a previous iteration was smaller than $1.0 \times 10^{-8}$, the iterations were terminated. This solution algorithm is more robust than that introduced by Shaver and coworkers [24].

\section{THE PURE-FLUID DATABASE}

A database of 20 pure compounds described previously by Shaver and coworkers [24] and Park [19] was used in this work. The database covers almost the entire vapor-liquid saturated region from the triple point to a reduced temperature of about 0.95 . For several compounds, only limited saturated liquid density data are available, and for six compounds only vapor pressures are used. Specific ranges of saturated data used for pure fluids and their sources are given in Table III. Additional data for heavy normal hydrocarbons $\left(\mathrm{C}_{20}, \mathrm{C}_{28}, \mathrm{C}_{36}\right.$ and $\left.\mathrm{C}_{44}\right)$ and hydrogen were also used to evaluate the pure component parameters in the equation for those compounds. The 
temperature, pressure and saturated density ranges for these heavy normal hydrocarbons and hydrogen with their sources are shown in Table III.

\section{RESULTS AND DISCUSSION}

The PGR EOS modifications discussed previously were evaluated. Errors in predicted vapor pressures for 20 selected compounds are shown in Table IV, along with those of the PR, SPHCT and PGR equations. The errors are expressed using the root-mean-squared error (RMSE) and the absolute-average-percentage deviation (\%AAD). The RMSE and \%AAD are defined as,

$$
\mathrm{RMSE}=\sqrt{\frac{\sum_{\mathrm{i}=1}^{\mathrm{N}}\left(\mathrm{Y}_{\text {calc }, \mathrm{i}}-\mathrm{Y}_{\text {exp }, \mathrm{i}}\right)^{2}}{\mathrm{~N}}}
$$

and

$$
\% \mathrm{AAD}=\frac{1}{\mathrm{~N}} \sum_{\mathrm{i}=1}^{\mathrm{N}}\left|\frac{\mathrm{Y}_{\text {calc }, \mathrm{i}}-\mathrm{Y}_{\text {exp }, \mathrm{i}}}{\mathrm{Y}_{\text {exp }, \mathrm{i}}}\right| \times 100
$$

respectively. In both equations, Y stands for a property being evaluated.

Table IV shows the results of the vapor pressure predictions for the modified PGR EOS along with the results obtained from the PR, original SPHCT and original PGR equations. The comparisons shown in Table IV are based on vapor pressures greater than 0.007 bar (0.1psia) and reduced temperatures less than 0.95. The SPHCT and PGR equations showed poor vapor pressure prediction below 0.007 bar $[13,24]$.

For vapor pressures, the overall RSME is 0.2 bar and the overall \%AAD is 1.3 . The overall \%AAD for the modified PGR equation is less than half of those for the PR and SPHCT equations and $20 \%$ less than that for the original PGR equation. The overall RSME of the modified PGR equation is less than the original PGR equation and one third that of the original SPHCT equation. Among these equations considered, the modified PGR EOS showed the best vapor pressure predictions. In fairness, it should be noted that the PR EOS did not benefit from system-specific regressed parameters as did the other equations. 
In the prediction of vapor pressures for argon, cyclobutane, and octane, the modified PGR equation performed worse than the PR equation while the modified PGR equation performed mostly better than the original SPHCT and the original PGR equations. Otherwise, the modified PGR equations gave better predictions than the PR equation, which implies the superiority of the segment-segment interactions model to that of molecule-molecule interactions model in predicting the vapor pressure for both heavy and light compounds. In comparison, for vapor pressures of carbon dioxide and a highly polar fluid, such as water, the original SPHCT and original PGR EOSs yielded worse results than the PR. This drawback is shown to be lessened using the modified PGR equation (\%AAD of 0.5 and 4.1, respectively); albeit, the RSME values of the modified PGR equation are higher than that of the PR. Accordingly, the performance of the modified PGR equation is generally better than the PR, the original SPHCT and the original PGR EOSs in predicting vapor pressures of pure fluids over the full saturation range.

Tables V and VI show the results for saturated liquid and vapor density predictions of the PR, original SPHCT, original PGR, and modified PGR equations. For saturated liquid densities, the overall RMSE of $0.02 \mathrm{~g} / \mathrm{cm}^{3}$ and \%AAD of 2.8 are obtained. In spite of its larger vapor pressure errors for argon, the modified PGR equation shows much better results for the liquid density of this component. Like the PR EOS, the modified PGR is observed to be less accurate than the original PGR equation for ethane. However, the overall performance for pure fluid liquid density predictions of the modified PGR EOS exceeds those of the PR, the original SPHCT, and the original PGR EOSs.

For saturated vapor densities, an overall RMSE of $0.007 \mathrm{~g} / \mathrm{cm}^{3}$ and \%AAD of 3.7 are obtained. The overall RSME and \%AAD of the modified equation are higher than those of the original PGR equation which are $0.005 \mathrm{~g} / \mathrm{c} \mathrm{m}^{3}$ and $3.1 \%$, respectively. The results show that the vapor density predictive capability of the modified equation exceeds that of the original SPHCT EOS and is comparable to that of the PR equation.

The modified equation is better than the PR, original SPHCT and original PGR equations in representing both vapor pressure and saturated liquid densities of pure fluids. While the PR and original PGR equations show comparable performance in predicting the saturated vapor 
densities of pure fluids (\%AAD of 3.6 and 3.1, respectively), the SPHCT equation showed the worst results for saturated vapor density predictions (\%AAD of 6.4).

Figure 6 shows the experimental and calculated phase envelop for propane. The calculated properties are obtained from the vapor-liquid equilibrium calculations at selected temperatures. As shown in Figure 6, the proposed equation provides accurate saturated liquid density predictions while larger deviations occur in calculating the saturated vapor densities near the critical points.

Table VII presents the pure-component parameters of the modified PGR EOS. The parameters follow the general behavior of those of the SPHCT and PGR equations. The characteristic temperature, $\mathrm{T}^{*}$, is proportional to the normal boiling point of the compound. The characteristic volume, $\mathrm{v}^{*}$, increases as the molecular size of the n-paraffin increases. The trend for the degree of freedom parameter, $\mathrm{c}$, is similar to the characteristic volume. Figures 7 to 9 show the pure-component parameters of several normal paraffins as a function of carbon number. In Figure 7, the characteristic temperature shows an asymptotic behavior as the carbon number increases; n-octane deviates slightly from the trend of the other paraffins. The characteristic volume and the degree of freedom parameter are almost linear relative to the carbon number of the compound. For heavier n-paraffins such as $\mathrm{C}_{20}, \mathrm{C}_{28}, \mathrm{C}_{36}$, and $\mathrm{C}_{44}$, accurate pure component parameter determinations were not easy due to the scarcity of available saturation data. For these components, both pure component and binary mixture data were used simultaneously to obtain the parameters. The resulting trends of the pure-component parameters are similar to those of the original SPHCT, modified SPHCT [24], and original PGR [19] EOSs.

\section{CONCLUSIONS}

The original Park-Gasem-Robinson (PGR) equation was modified to enhance its volumetric and equilibrium predictive capabilities. The two temperature-dependent terms in the attractive part of the equation were replaced with a new simpler term, which was tested for its numerical stability. The universal EOS constants and the pure component parameters for selected compounds were obtained for the modified version of the PGR EOS. A study of the modified PGR equation parameters $\left(\mathrm{T}^{*}, \mathrm{v}^{*}, \mathrm{c}\right)$ was performed to gain insight into the sensitivity of 
calculated properties to the equation parameters and to investigate the behavior of the parameters required to produce accurate vapor-liquid equilibrium calculations. The vapor pressure and saturated phase density calculations showed higher sensitivity to the characteristic temperature, $\mathrm{T}^{*}$. As such, further refinement of the attractive portion of the EOS is possible.

For most of the systems, the modified equation performed better than the PR, SPHCT and original PGR equations in representing vapor pressures and saturated phase densities. However, the modified PGR EOS produces larger deviations in the saturated vapor densities near the critical region, which is expected of an analytic EOS.

\section{NOMENCLATURE}

$\begin{array}{ll}\mathrm{c} & \text { Degree of freedom parameter } \\ \mathrm{k} & \text { Constant } \\ \mathrm{N} & \text { Number of data points; number of moles } \\ \mathrm{p} & \text { Pressure } \\ \mathrm{Q} & \text { Equation of state constant } \\ \mathrm{SS} & \text { Objective function } \\ \mathrm{T} & \text { Temperature } \\ \mathrm{T}^{*} & \text { Characteristic temperature parameter } \\ \tilde{\mathrm{T}}_{\mathrm{N}} & \text { Reduced temperature (T/T*) } \\ \mathrm{u} & \text { Equation of state constant } \\ \mathrm{V}^{*} & \text { Characteristic volume parameter } \\ \mathrm{v} & \text { molar volume } \\ \mathrm{W} & \text { Equation of state constant } \\ \mathrm{Y} & \text { Temperature-dependent function in the new equation of state at low density } \\ & \text { limit } \\ \mathrm{Z} & \text { Compressibility factor }\end{array}$




\section{Greek letters}

$\alpha \quad$ Temperature-dependent parameter in cubic equation of state; temperature correction function

$\beta_{1}, \beta_{2} \quad$ Constants in repulsive term of the new equation of state

$\rho \quad$ Density

$\eta \quad$ Reduced density $\left(\tau \mathrm{v}^{*} / \mathrm{v}\right)$

$\kappa \quad$ Equation of state constant

$\tau \quad$ Geometrical constant (0.74048)

$\omega \quad$ Constant

\section{Subscripts}

calc Calculated

exp Experimental

$\mathrm{i}, \mathrm{j} \quad$ Component or data point identification number

$1 \quad$ Liquid

r $\quad$ Reduced property

V Vapor

\section{Superscripts}

$\begin{array}{ll}\text { att } & \text { Attractive } \\ \text { rep } & \text { Repulsive } \\ * & \text { Characteristic parameter }\end{array}$




\section{Literature Cited}

1. Alder, B. J., D. A. Young and M. A. Mark, "Studies in Molecular Dynamics. I. Corrections to the Augmented van der Waals Theory for Square-Well Fluids," J. Chemical Physics, 56, 3013, 1972.

2. Anderko, A., "Equation-of-State Methods for the Modeling of Phase Equilibria," Fluid Phase Equilibria, 61, 145, 1990.

3. Angus, S., B. Armstrong and K. M. de Reuck, International Thermodynamic Tables of the Fluid State - 5. Methane, International Union of Pure and Applied Chemistry, Pergamon Press, New York, 1976.

4. Beret, S. and J. M. Prausnitz, "Perturbed Hard-Chain Theory: An Equation of State for Fluids Containing Small or Large Molecules," AIChE Journal, 21, 1123, 1975.

5. Bokis, C. P., M. D. Donohue and C. K. Hall, "A Local Composition Model for Square-Well Chains Using the Generalized Flory Dimer Theory," J. Physical Chemistry, 96, 11004, 1992.

6. Carnahan, N. F. and K. E. Starling, "Equation of State for Nonattracting Rigid Spheres," J. Chemical Physics, 51, 635, 1969.

7. Ciocca, G. and I. Nagata, "Density Dependence of the External Degrees of Freedom: Application to a Simplified Version of the Perturbed Hard Chain Theory," Fluid Phase Equilibria, 41, 59, 1988.

8. De Santis, R., F. Gironi and L. Marrelli, "Vapor-Liquid Equilibrium from a Hard-Sphere Equation of State," Ind. Eng. Chem. Fundam., 15, 183, 1976.

9. Dickman, R. and C. K. Hall, "High Density Monte Carlo Simulations of Chain Molecules: Bulk Equation of State and Density Profile Near Walls," J. Chemical Physics, 89, 3168, 1988.

10. Donohue, M. D. and J. M. Prausnitz, "Perturbed Hard Chain Theory for Fluid Mixtures: Thermodynamic Properties for Mixtures in Natural Gas and Petroleum Technology," AIChE Journal, 24, 849, 1978.

11. Elliott, Jr., J. R., S. J. Sresh and M. D. Donohue, "A Simple Equation of State for Nonspherical and Associating Molecules," Ind. Eng. Chem. Res., 29, 1476, 1990.

12. Erpenbeck, J. J. and W. W. Wood, "Molecular Dynamics Calculations of the Hard-Sphere Equation of State," J. Statistical Physics, 35 (3/4), 320, 1984.

13. Gasem, K. A. M. and R. L. Robinson, Jr., "Evaluation of the Simplified Perturbed Hard Chain Theory (SPHCT) for Prediction of Phase Behavior of n-Paraffins and Mixtures of nParaffins with Ethane," Fluid Phase Equilibria, 58, 13, 1990.

14. Gasem, K. A. M., Ph.D. Dissertation, Binary Vapor-Liquid Phase Equilibrium for Carbon Dioxide + Heavy Normal Paraffins, Oklahoma State University, Stillwater, Oklahoma, 1986.

15. Kim, C. H., P. Vimalchand, M. D. Donohue and S. I. Sandler, "Local Composition Model for Chainlike Molecules: A New Simplified Version of the Perturbed Hard Chain Theory," AIChE Journal, 32, 1726, 1986. 
16. Lee, K. H., M. Lombardo and S. I. Sandler, "The Generalized van der Waals Partition Function. II. Application to the Square-Well Fluid," Fluid Phase Equilibria, 21, 177, 1985.

17. Nagata, I. and S. Yasuda, "On the Carnahan-Starling Equation of State," J. Chem. Eng. of Japan, 10 (1), 64, 1977.

18. Nakamura, R., G. J. F. Breedveld and J. M. Prausnitz, "Thermodynamic Properties of Gas Mixtures Containing Common Polar and Nonpolar Components," Ind. Eng. Chem. Proc. Des. Dev., 15, 557, 1976.

19. Park, J. K., Ph.D. Dissertation, Binary Vapor-Liquid Equilibrium Measurements for Selected Asymmetric Mixtures and Equation of State Development, Oklahoma State University, Stillwater, Oklahoma, 1994.

20. Peng, Y. D. and D. B. Robinson, "A New Two-Constant Equation of State," Ind. Eng. Chem. Fundam., 15, 59, 1976.

21. Ree, F. H. and W. G. Hoover, "Fifth and Sixth Coefficients for Hard Spheres and Hard Disks," J. Chemical Physics, 40, 939, 1964.

22. Sandler, S. I., H. Orbey and B. I. Lee, Models for Thermodynamic and Phase Equilibria Calculation, Marcel Dekker, New York, 1994.

23. Shaver, R. D., Ph.D. Dissertation, Vapor-Liquid Equilibrium Measurements for Selected Ethane and Carbon Dioxide Mixtures and Modification of the SPHCT Equation of State; Oklahoma State University, Stillwater, Oklahoma, 1993.

24. Shaver, R. D., R. L. Robinson, Jr. and K. A. M. Gasem, "Modified SPHCT EOS for Improved Predictions of Equilibrium and Volumetric Properties of Pure Fluids," Fluid Phase Equilibria, 112, 223, 1995.

25. Soave, G., "Equilibrium Constants from a Modified Redlich-Kwong Equation of State," Chemical Engineering Science, 27, 1197, 1972.

26. Vimalchand, P., A. Thomas, I. G. Economou and M. D. Donohue, "Effect of Hard-Sphere Structure on Pure-Component Equation of State Calculations," Fluid Phase Equilibria, 73, 39, 1992.

27. Row, K. H, Ph.D. Dissertation, Evaluation of the Modified Park-Gasem-Robinson Equation of State and Calculation of Calorimetric Properties Using Equations of State, Oklahoma State University, Stillwater, Oklahoma, 1994.

28. Angus, S., B. Armstrong and K. M. de Reuck, International Thermodynamic Tables of the Fluid State - 5. Methane, International Union of Pure and Applied Chemistry, Pergamon Press, New York, 1976.

29. Goodwin, R. D., H. M. Roder and G. C. Straty, Thermophysical Properties of Ethane from 90 to $600 \mathrm{~K}$ at Pressures to 700 Bars, NBS, Boulder, Colorado, 1976.

30. Goodwin, R. D. and W. M. Haynes, Thermophysical Properties of Propane from 85 to $700 \mathrm{~K}$ at Pressures to $70 \mathrm{MPa}$, NBS Monogram 170, Boulder, Colorado, 1981.

31. Haynes, W. M. and R. D. Goodwin, Thermophysical Properties of Normal Butane from 135 to $700 \mathrm{~K}$ at Pressures to $70 \mathrm{MPa}$, NBS Monogram 169, Boulder, Colorado, 1982. 
32. Vargaftik, N. B., Tables on the Thermophysical Properties of Liquids and Gases, John Wiley and sons, New York, 1975.

33. API Research Project 44, Selected Values of Properties of Hydrocarbons and Related Compounds, Thermodynamic Research Center, Texas A\&M College, College Station, Texas, 1972.

34. Younglove, B. A., "Thermophysical Properties of Fluids. I. Argon, Ethylene, Parahydrogen, Nitrogen, Nitrogen Trifluoride, and Oxygen," J. Physical and Chemical Reference Data, Vol. 11, Supplement No. 1, 1982.

35. Angus, S., B. Armstrong and K. M. de Reuck, International Thermodynamic Tables of the Fluid State - 7. Propylene (Propene), International Union of Pure and Applied Chemistry, Pergamon Press, New York, 1980.

36. Goodwin, R. D., "Benzene Thermophysical Properties from 279 to $900 \mathrm{~K}$ at Pressures to 1000 Bar," J. Physical and Chemical Reference Data, 17, 1541, 1988.

37. Perry, R. H., D. W. Green and J. O. Maloney, eds., Perry's Chemical Engineers Handbook, Sixth Edition, McGraw-Hill, New York, 1984.

38. Ely, J. F., J. W. Magee and W. M. Haynes, Thermophysical Properties for Special High $\mathrm{CO}_{2}$ Content Mixtures, Gas Processors Association, RR-110, 1987.

39. Haar, L., J. S. Gallager and G. S. Kell, NBS/NRC Steam Tables, McGraw-Hill, New York, 1984. 
TABLE I

EVALUATION OF MODIFYING FUNCTIONS FOR THE REPULSIVE AND ATTRACTIVE PORTION OF THE PGR EQUATION

\begin{tabular}{|c|c|c|c|}
\hline \multirow[t]{2}{*}{$\begin{array}{l}\text { Function } \\
\text { Included }\end{array}$} & \multirow[t]{2}{*}{$\begin{array}{l}\text { Number of } \\
\text { Constants }\end{array}$} & \multicolumn{2}{|c|}{$\begin{array}{c}\text { Vapor Pressure Predictions, } \\
\text { \% AAD }\end{array}$} \\
\hline & & $\begin{array}{c}\text { Carnahan and } \\
\text { Starling [6] }\end{array}$ & $\begin{array}{c}\text { Elliott et al. } \\
{[11]} \\
\end{array}$ \\
\hline$\alpha^{*}$ & 4 & 6.3 & 2.0 \\
\hline $\mathrm{F}_{\mathrm{t}}^{* *}$ & 4 & 5.9 & 1.0 \\
\hline$\alpha$ and $F_{t}$ & 8 & 5.7 & 1.0 \\
\hline
\end{tabular}




\section{TABLE II}

UNIVERSAL CONSTANTS FOR THE MODIFIED PGR EQUATION OF STATE

\begin{tabular}{cc}
\hline Constant & Value \\
\hline$\tau$ & 0.74048 \\
$\mathrm{u}$ & -2.8969 \\
$\mathrm{w}$ & 2.6944 \\
$\mathrm{Q}_{1}$ & 10.5121 \\
$\mathrm{Q}_{2}$ & 1.0226 \\
$\mathrm{Z}_{\mathrm{M}}$ & 1.4264 \\
$\omega_{1}$ & 0.076354 \\
$\omega_{2}$ & 2.0124 \\
$\omega_{3}$ & -0.22322 \\
$\omega_{4}$ & -0.70301 \\
\hline
\end{tabular}


TABLE III

SOURCES AND RANGES OF PURE FLUID SATURATION DATA

\begin{tabular}{|c|c|c|c|c|c|}
\hline $\begin{array}{l}\text { Compound } \\
\text { (No. of pts) }\end{array}$ & $\begin{array}{l}\text { Temperature } \\
\text { Range, } \mathrm{K}\end{array}$ & $\begin{array}{l}\text { Pressure } \\
\text { Range, bar }\end{array}$ & $\begin{array}{l}\text { Liquid Density } \\
\text { Range, } \mathrm{g} / \mathrm{cm}^{3}\end{array}$ & $\begin{array}{l}\text { Vapor Density } \\
\text { Range, } \mathrm{g} / \mathrm{cm}^{3}\end{array}$ & Source \\
\hline Methane (9) & $90.68-188.0$ & $0.1172-42.412$ & $0.2299-0.4512$ & $2.514 \times 10^{-4}-0.0986$ & 3 \\
\hline Ethane (9) & $90.348-295.0$ & $1.131 \times 10^{-5}-39.16$ & $0.3309-0.6519$ & $4.557 \times 10^{-8}-0.0925$ & 28 \\
\hline Propane (26) & $85.47-360.0$ & $3.0 \times 10^{-9}-35.55$ & $0.3453-0.6574$ & $2.72 \times 10^{-5}-0.1054$ & 29 \\
\hline Butane (12) & $134.86-420.0$ & $6.736 \times 10^{-6}-34.83$ & $0.3281-0.7353$ & $3.492 \times 10^{-8}-0.1335$ & 30 \\
\hline Octane (8) & $243.15-553.15$ & $3.16 \times 10^{-4}-19.97$ & $0.3818-0.7102$ & $0.0003-0.09873$ & 31 \\
\hline Decane (12) & $330.85-613.15$ & $0.01333-20.366$ & $0.324-0.6996$ & $*$ & 32 \\
\hline Tetradecane (11) & $394.26-573.15$ & $0.0129-2.605$ & $0.6685^{* *}$ & $*$ & 32 \\
\hline Ethene (12) & $103.986-276.0$ & $0.0012-43.73$ & $0.3242-0.6549$ & $4.01 \times 10^{-6}-0.1115$ & 33 \\
\hline Propene (11) & $87.89-360.0$ & $9.54 \times 10^{-9}-42.202$ & $0.3292-0.7688$ & $5.49 \times 10^{-11}-0.1338$ & 34 \\
\hline 1-Butene (12) & $119.95-413.15$ & $5.0 \times 10^{-7}-36.18$ & $0.345-0.618$ & $*$ & 32 \\
\hline 1-Hexene (12) & $156.15-493.15$ & $5.0 \times 10^{-7}-26.86$ & $*$ & $*$ & 32 \\
\hline Cyclopropane (12) & $171.85-393.15$ & $0.01333-51.252$ & $*$ & $*$ & 32 \\
\hline Cyclobutane (13) & $204.95-453.15$ & $0.01333-45.191$ & $*$ & $*$ & 32 \\
\hline Cyclohexane (15) & $279.82-543.15$ & $0.05328-35.889$ & $0.3130-0.7102$ & $*$ & 32 \\
\hline
\end{tabular}


TABLE III (Continued)

\begin{tabular}{|c|c|c|c|c|c|}
\hline Compound & $\begin{array}{l}\text { Temperature } \\
\text { Range, K }\end{array}$ & $\begin{array}{l}\text { Pressure } \\
\text { Range, bar }\end{array}$ & $\begin{array}{l}\text { Liquid Density } \\
\text { Range, } \mathrm{g} / \mathrm{cm}^{3}\end{array}$ & $\begin{array}{l}\text { Vapor Density } \\
\text { Range, } \mathrm{g} / \mathrm{cm}^{3}\end{array}$ & Source \\
\hline Cyclooctane (17) & $308.45-633.15$ & $0.01333-31.309$ & $*$ & $*$ & 32 \\
\hline trans-Decalin (9) & $334.06-492.03$ & $0.01333-1.9998$ & $0.7726-0.8355$ & $*$ & 32 \\
\hline Benzene (10) & $278.68-555.0$ & $0.0478-44.8502$ & $0.4355-0.8965$ & $1.62 \times 10^{-4}-0.1750$ & 35 \\
\hline Toluene (12) & $270.0-580.0$ & $0.0076-35.56$ & $0.2914-0.8873$ & $2.87 \times 10^{-5}-0.1318$ & 36 \\
\hline Argon (8) & $84.0-146.0$ & $0.7052-49.05$ & $0.8296-1.413$ & $0.004194-0.2680$ & 33 \\
\hline Carbon Dioxide (17) & $216.55-298.15$ & $5.179-64.356$ & $0.7138-1.1778$ & $0.0138-0.2424$ & 37 \\
\hline Water (14) & $273.16-633.15$ & $\begin{array}{l}0.006117- \\
186.55\end{array}$ & $0.5281-0.9998$ & $4.855 \times 10^{-6}-0.1437$ & 38 \\
\hline Eicosane (5) & $473.15-623.15$ & $0.01533-1.110$ & $0.5903-0.6668$ & $*$ & 32 \\
\hline Octacosane (5) & $323.15-704.45$ & $7.0 \times 10^{-9}-1.0133$ & $0.6226-0.7876$ & $*$ & 32 \\
\hline Hexatriacontane (6) & $373.15-769.15$ & $6.9 \times 10^{-8}-1.0133$ & $0.6399-0.7667$ & $*$ & 32 \\
\hline Tetratetracontane (5) & $373.15-818.15$ & $6.9 \times 10^{-8}-1.0133$ & $0.7450-0.7760$ & $*$ & 32 \\
\hline
\end{tabular}

\footnotetext{
* Saturated density data for these compounds was not available.

** Only one saturated liquid density value was available for tetradecane.
} 
TABLE IV

EVALUATION OF PURE FLUID VAPOR PRESSURE PREDICTIONS

\begin{tabular}{|c|c|c|c|c|c|c|c|c|}
\hline \multirow[b]{2}{*}{ Component } & \multicolumn{2}{|c|}{ Peng-Robinson } & \multicolumn{2}{|c|}{ SPHCT } & \multicolumn{2}{|c|}{ PGR } & \multicolumn{2}{|c|}{ This Work } \\
\hline & $\begin{array}{c}\text { RMSE } \\
\text { bar }\end{array}$ & $\% \mathrm{AAD}$ & $\begin{array}{c}\text { RMSE } \\
\text { bar }\end{array}$ & $\% \mathrm{AAD}$ & $\begin{array}{c}\text { RMSE } \\
\text { bar }\end{array}$ & $\% \mathrm{AAD}$ & $\begin{array}{c}\text { RMSE } \\
\text { bar }\end{array}$ & $\% \mathrm{AAD}$ \\
\hline Methane & 0.162 & 1.6 & 0.444 & 3.8 & 0.383 & 1.6 & 0.032 & 0.5 \\
\hline Ethane & 0.075 & 3.5 & 0.721 & 4.4 & 0.685 & 2.5 & 0.536 & 2.2 \\
\hline Propane & 0.074 & 5.8 & 0.721 & 3.7 & 0.053 & $0^{+}$ & 0.203 & 0.8 \\
\hline Butane & 0.094 & 1.7 & 0.764 & 4.5 & 0.311 & 1.7 & 0.100 & 0.5 \\
\hline Octane & 0.050 & 2.0 & 0.408 & 4.2 & 0.259 & 2.5 & 0.258 & 2.1 \\
\hline Decane & 0.063 & 3.9 & 0.489 & 3.6 & 0.551 & 2.2 & 0.424 & 2.7 \\
\hline Tetradecane & 0.030 & 7.3 & 0.021 & 1.3 & 0.036 & 1.8 & 0.014 & 0.7 \\
\hline Ethene & 0.056 & 2.8 & 0.923 & 4.1 & 0.719 & 2.1 & 0.077 & 2.6 \\
\hline Propene & 0.053 & 1.2 & 0.655 & 4.0 & 0.710 & 2.3 & 0.203 & 1.1 \\
\hline 1-Butene & 0.052 & 10.3 & 0.685 & 3.3 & 0.271 & 0.8 & 0.247 & 0.9 \\
\hline 1-Hexene & 0.039 & 1.1 & 0.227 & 0.9 & 0.171 & 1.6 & 0.158 & 0.8 \\
\hline Cyclopropane & 0.072 & 1.6 & 0.384 & 1.0 & 0.150 & 0.5 & 0.086 & 0.5 \\
\hline Cyclobutane & 0.061 & 0.5 & 0.378 & 1.2 & 0.411 & 0.9 & 0.286 & 1.1 \\
\hline Cyclohexane & 0.029 & 2.1 & 0.668 & 2.2 & 0.284 & 1.0 & 0.283 & 0.7 \\
\hline Cyclooctane & 0.176 & 7.3 & 1.029 & 4.0 & 0.182 & 1.0 & 0.207 & 1.2 \\
\hline trans-Decalin & 0.049 & 11.9 & 0.009 & 0.8 & 0.002 & 0.1 & 0.004 & 0.3 \\
\hline Benzene & 0.082 & 2.1 & 0.447 & 3.8 & 0.963 & 2.7 & 0.522 & 2.1 \\
\hline Toluene & 0.056 & 1.8 & 1.105 & 4.1 & 0.162 & 1.0 & 0.145 & 1.0 \\
\hline Argon & 0.110 & 0.4 & 0.338 & 2.3 & 1.012 & 2.7 & 0.609 & 1.8 \\
\hline Carbon Dioxide & 0.344 & 2.2 & 0.651 & 3.0 & 0.582 & 2.3 & 0.384 & 0.5 \\
\hline Water & 0.829 & 4.7 & 3.763 & 7.0 & 4.824 & 6.5 & 1.792 & 4.1 \\
\hline Overall & 0.243 & 3.8 & 1.094 & 3.3 & 1.268 & 1.7 & 0.207 & 1.3 \\
\hline
\end{tabular}


TABLE V

EVALUATION OF PURE FLUID LIQUID DENSITY PREDICTIONS

\begin{tabular}{|c|c|c|c|c|c|c|c|c|}
\hline \multirow[b]{2}{*}{ Component } & \multicolumn{2}{|c|}{ Peng-Robinson } & \multicolumn{2}{|c|}{ SPHCT } & \multicolumn{2}{|c|}{ PGR } & \multicolumn{2}{|c|}{ This Work } \\
\hline & $\begin{array}{c}\text { RMSE } \\
\mathrm{g} / \mathrm{cm}^{3}\end{array}$ & $\% \mathrm{AAD}$ & $\begin{array}{c}\text { RMSE } \\
\mathrm{g} / \mathrm{cm}^{3}\end{array}$ & $\% \mathrm{AAD}$ & $\begin{array}{c}\text { RMSE } \\
\mathrm{g} / \mathrm{cm}^{3}\end{array}$ & $\% \mathrm{AAD}$ & $\begin{array}{c}\text { RMSE } \\
\mathrm{g} / \mathrm{cm}^{3}\end{array}$ & $\% \mathrm{AAD}$ \\
\hline Methane & 0.036 & 8.8 & 0.028 & 7.0 & 0.017 & 4.6 & 0.004 & 1.1 \\
\hline Ethane & 0.030 & 5.5 & 0.045 & 7.8 & 0.010 & 2.1 & 0.013 & 2.8 \\
\hline Propane & 0.032 & 5.6 & 0.047 & 7.8 & 0.014 & 2.7 & 0.012 & 2.1 \\
\hline Butane & 0.029 & 5.0 & 1.049 & 7.9 & 0.022 & 4.3 & 0.017 & 2.8 \\
\hline Octane & 0.030 & 5.2 & 0.062 & 9.9 & 0.042 & 7.7 & 0.042 & 7.1 \\
\hline Decane & 0.043 & 7.2 & 0.068 & 11.5 & 0.028 & 4.9 & 0.008 & 0.9 \\
\hline Tetradecane & 0.079 & 8.8 & 0.002 & 0.3 & 0.020 & 2.9 & 0.000 & 0.2 \\
\hline Ethene & 0.041 & 7.1 & 0.037 & 7.4 & 0.011 & 2.2 & 0.016 & 2.7 \\
\hline Propene & 0.041 & 6.6 & 0.039 & 7.6 & 0.022 & 4.2 & 0.020 & 3.6 \\
\hline 1-Butene & 0.024 & 3.9 & 0.024 & 3.7 & 0.017 & 2.9 & 0.020 & 2.9 \\
\hline Cyclohexane & 0.018 & 2.6 & 0.029 & 4.1 & 0.022 & 3.9 & 0.017 & 2.0 \\
\hline Benzene & 0.038 & 5.6 & 0.072 & 9.3 & 0.043 & 6.2 & 0.042 & 6.1 \\
\hline Toluene & 0.027 & 2.9 & 0.060 & 7.2 & 0.033 & 4.8 & 0.027 & 3.3 \\
\hline Argon & 0.145 & 10.0 & 0.077 & 5.9 & 0.018 & 1.4 & 0.014 & 1.0 \\
\hline Carbon Dioxide & 0.047 & 4.4 & 0.051 & 4.5 & 0.047 & 4.5 & 0.048 & 4.3 \\
\hline Water & 0.156 & 19.5 & 0.077 & 8.3 & 0.032 & 3.6 & 0.041 & 3.4 \\
\hline Overall & 0.062 & 6.8 & 0.052 & 6.9 & 0.028 & 3.8 & 0.017 & 2.8 \\
\hline
\end{tabular}


TABLE VI

EVALUATION OF PURE FLUID VAPOR DENSITY PREDICTIONS

\begin{tabular}{|c|c|c|c|c|c|c|c|c|}
\hline \multirow[b]{2}{*}{ Component } & \multicolumn{2}{|c|}{ Peng-Robinson } & \multicolumn{2}{|c|}{ SPHCT } & \multicolumn{2}{|c|}{ PGR } & \multicolumn{2}{|c|}{ This work } \\
\hline & $\begin{array}{l}\text { RMSE } \\
\mathrm{g} / \mathrm{cm}^{3}\end{array}$ & $\% \mathrm{AAD}$ & $\begin{array}{l}\text { RMSE } \\
\mathrm{g} / \mathrm{cm}^{3}\end{array}$ & $\% \mathrm{AAD}$ & $\begin{array}{c}\text { RMSE } \\
\mathrm{g} / \mathrm{cm}^{3}\end{array}$ & $\% \mathrm{AAD}$ & $\begin{array}{c}\text { RMSE } \\
\mathrm{g} / \mathrm{cm}^{3}\end{array}$ & $\% \mathrm{AAD}$ \\
\hline Methane & 0.002 & 3.1 & 0.007 & 6.6 & 0.006 & 5.0 & 0.002 & 3.4 \\
\hline Ethane & 0.001 & 4.0 & 0.006 & 7.1 & 0.002 & 2.0 & 0.003 & 2.2 \\
\hline Propane & 0.001 & 6.1 & 0.006 & 5.3 & 0.004 & 3.6 & 0.003 & 2.7 \\
\hline Butane & 0.001 & 2.1 & 0.010 & 6.5 & 0.005 & 2.2 & 0.002 & 2.6 \\
\hline Octane & 0.001 & 2.3 & 0.009 & 8.1 & 0.005 & 4.1 & 0.006 & 4.4 \\
\hline Ethene & 0.001 & 2.9 & 0.008 & 6.5 & 0.002 & 1.7 & 0.003 & 3.9 \\
\hline Propene & 0.000 & 1.6 & 0.009 & 6.1 & 0.003 & 1.5 & 0.005 & 2.5 \\
\hline Benzene & 0.002 & 2.8 & 0.014 & 7.1 & 0.008 & 3.0 & 0.009 & 3.4 \\
\hline Toluene & 0.004 & 4.0 & 0.009 & 5.1 & 0.003 & 2.2 & 0.001 & 1.8 \\
\hline Argon & 0.003 & 1.4 & 0.014 & 4.0 & 0.003 & 1.4 & 0.007 & 1.6 \\
\hline Carbon Dioxide & 0.001 & 2.7 & 0.015 & 4.6 & 0.007 & 2.3 & 0.012 & 5.3 \\
\hline Water & 0.003 & 6.0 & 0.017 & 11.3 & 0.010 & 6.6 & 0.015 & 8.6 \\
\hline Overall & 0.002 & 3.6 & 0.011 & 6.4 & 0.006 & 3.1 & 0.007 & 3.7 \\
\hline
\end{tabular}


TABLE VII

PURE FLUID PARAMETERS FOR THE MODIFIED PGR EQUATION OF STATE

\begin{tabular}{|c|c|c|c|}
\hline Compound & $\begin{array}{l}\mathrm{T}^{*} \\
(\mathrm{~K})\end{array}$ & $\begin{array}{c}\mathrm{v}^{*} \\
\left(\mathrm{~cm}^{3} / \mathrm{mol}\right)\end{array}$ & $\mathrm{c}$ \\
\hline Methane & 81.217 & 20.413 & 1.0000 \\
\hline Ethane & 116.67 & 27.809 & 1.3459 \\
\hline Propane & 137.74 & 37.752 & 1.4821 \\
\hline Butane & 151.59 & 46.941 & 1.6862 \\
\hline Octane & 180.89 & 79.449 & 2.5204 \\
\hline Decane & 191.32 & 90.444 & 2.8887 \\
\hline Tetradecane & 199.87 & 137.78 & 3.7097 \\
\hline Eicosane & 213.75 & 180.99 & 4.6851 \\
\hline Octacosane & 212.96 & 249.00 & 6.6735 \\
\hline Hexatriacontane & 208.07 & 307.01 & 9.4587 \\
\hline Tetratetracontane & 212.25 & 345.81 & 10.889 \\
\hline Ethene & 107.38 & 25.880 & 1.3452 \\
\hline Propene & 133.45 & 34.359 & 1.5260 \\
\hline 1-Butene & 150.31 & 44.345 & 1.6533 \\
\hline 1-Hexene & 169.65 & 63.663 & 2.0272 \\
\hline Cyclopropane & 140.11 & 37.070 & 1.5685 \\
\hline Cyclobutane & 180.86 & 32.561 & 1.4232 \\
\hline Cyclohexane & 197.62 & 53.480 & 1.7204 \\
\hline Cyclooctane & 231.08 & 61.238 & 1.8287 \\
\hline trans-Decalin & 207.06 & 123.79 & 2.4176 \\
\hline Benzene & 196.03 & 44.800 & 1.8007 \\
\hline Toluene & 203.28 & 55.991 & 1.9281 \\
\hline Argon & 62.793 & 15.451 & 1.0269 \\
\hline Carbon Dioxide & 106.02 & 16.096 & 1.8331 \\
\hline Water & 228.95 & 9.4878 & 1.9452 \\
\hline Hydrogen & 20.556 & 18.434 & 0.38545 \\
\hline
\end{tabular}




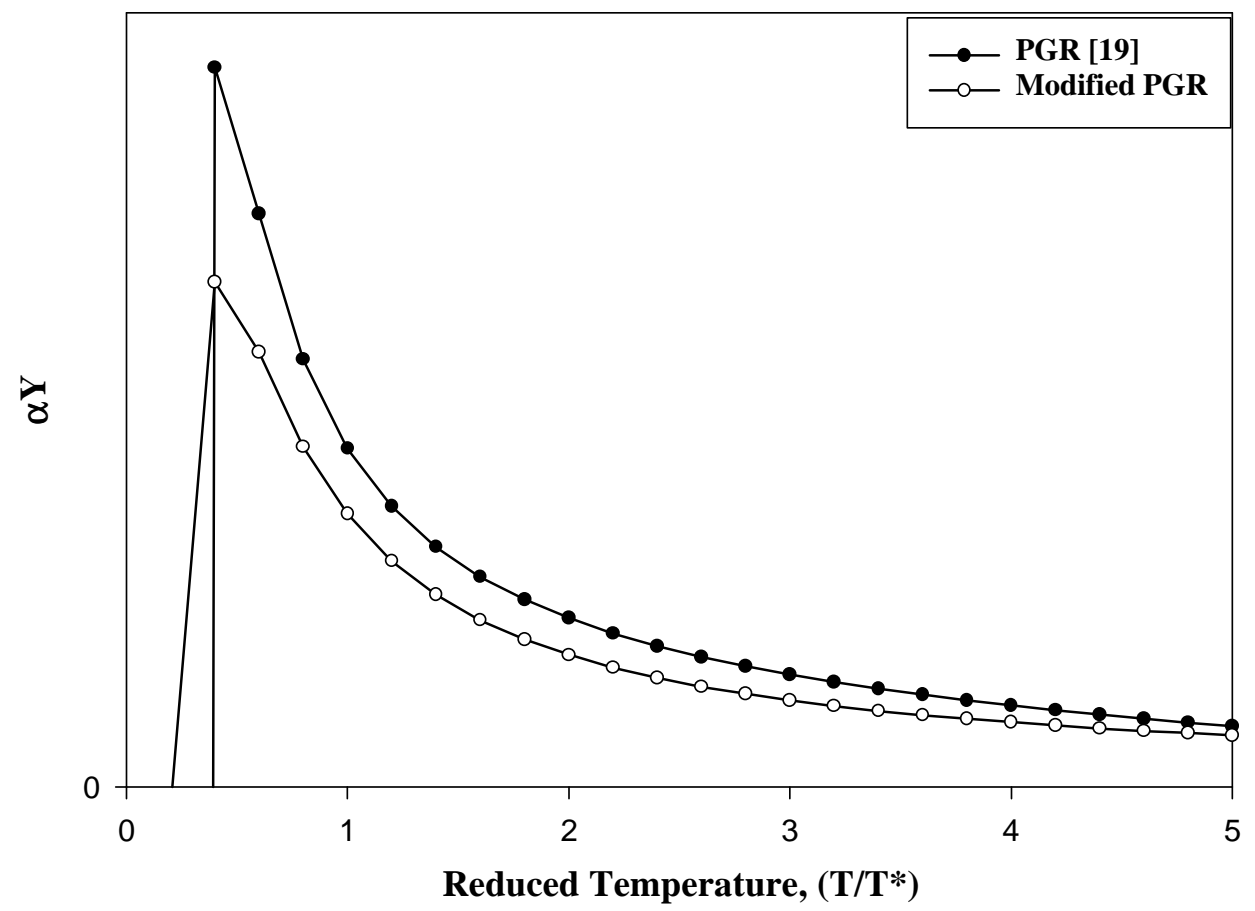

Figure 1. The Temperature Dependence of the Attractive Term. 


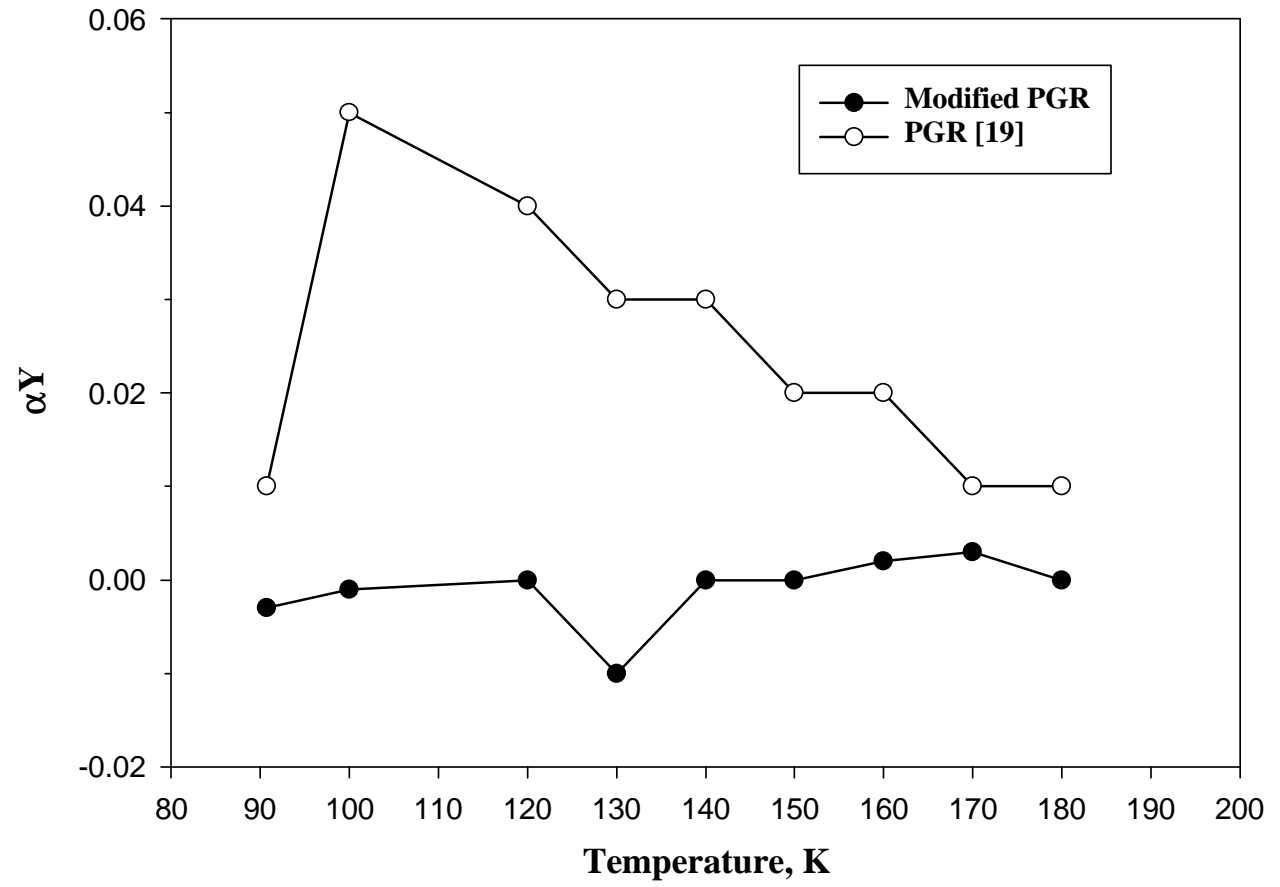

Figure 2. Comparison of Calculated and Regressed Values of $(\alpha \mathrm{Y})$ for Methane. 


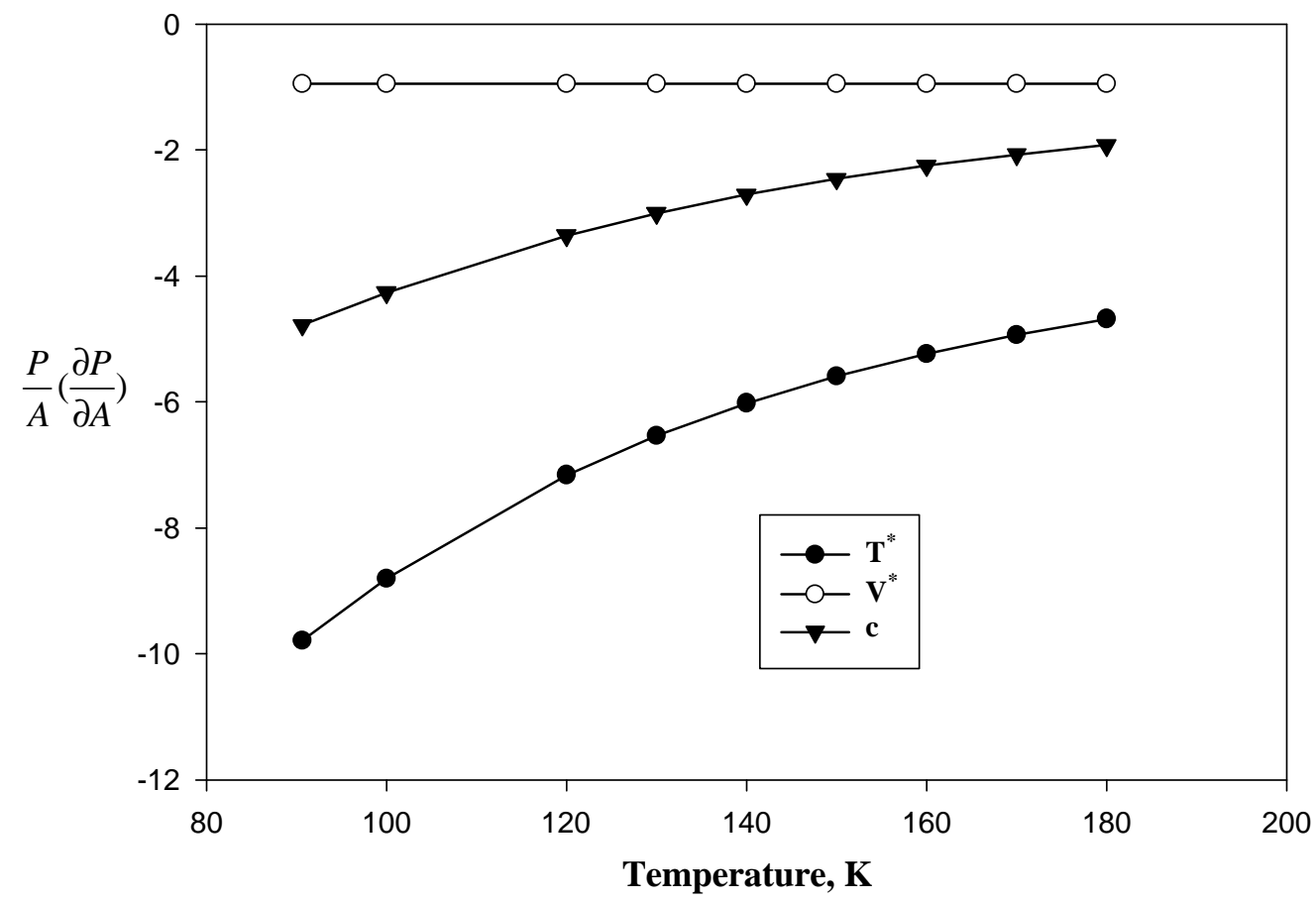

Figure 3. Effect of Temperature on Vapor Pressure Sensitivity for Saturated Methane. 


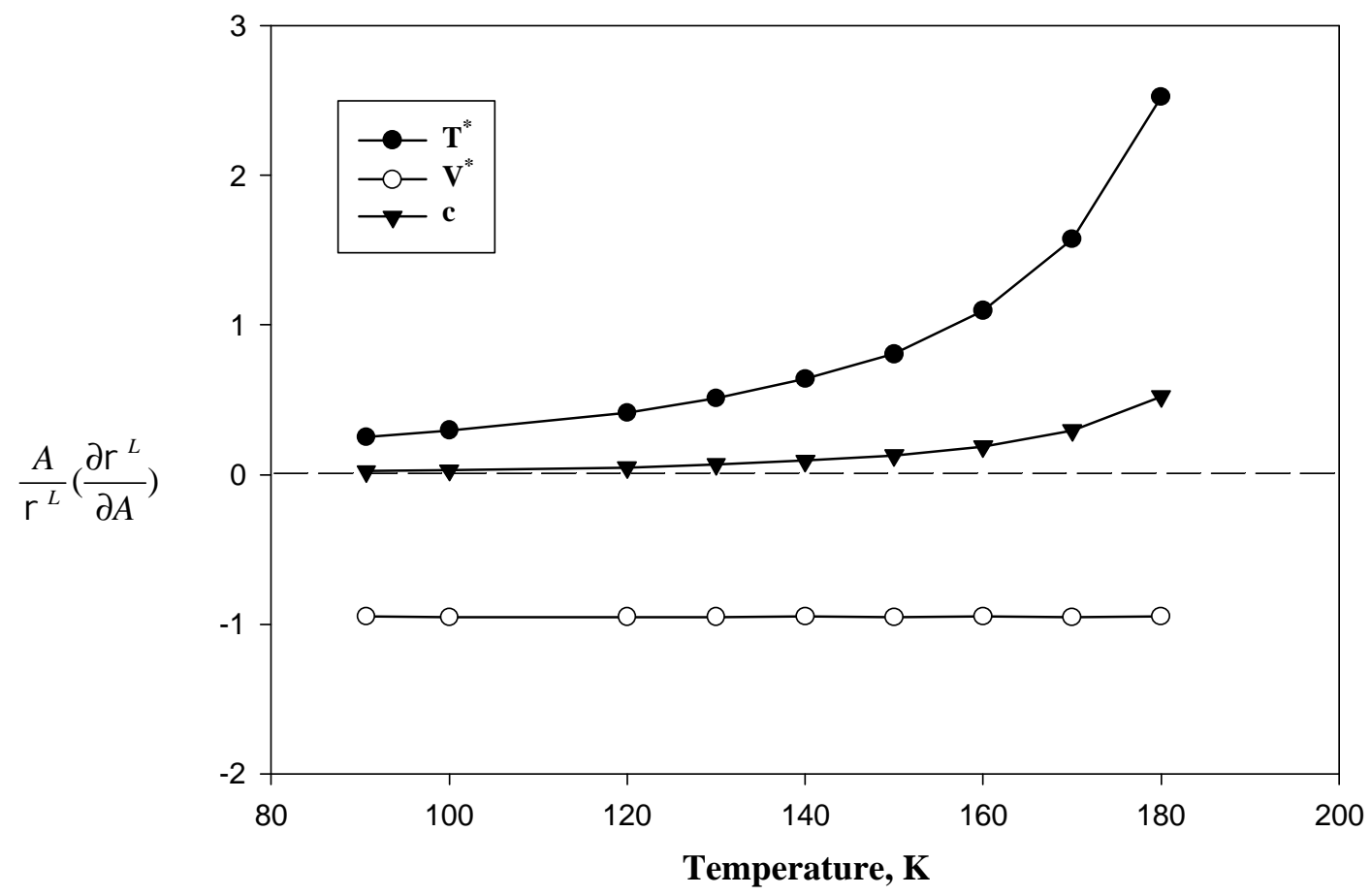

Figure 4. Effect of Temperature on Liquid Density Sensitivity for Saturated Methane. 


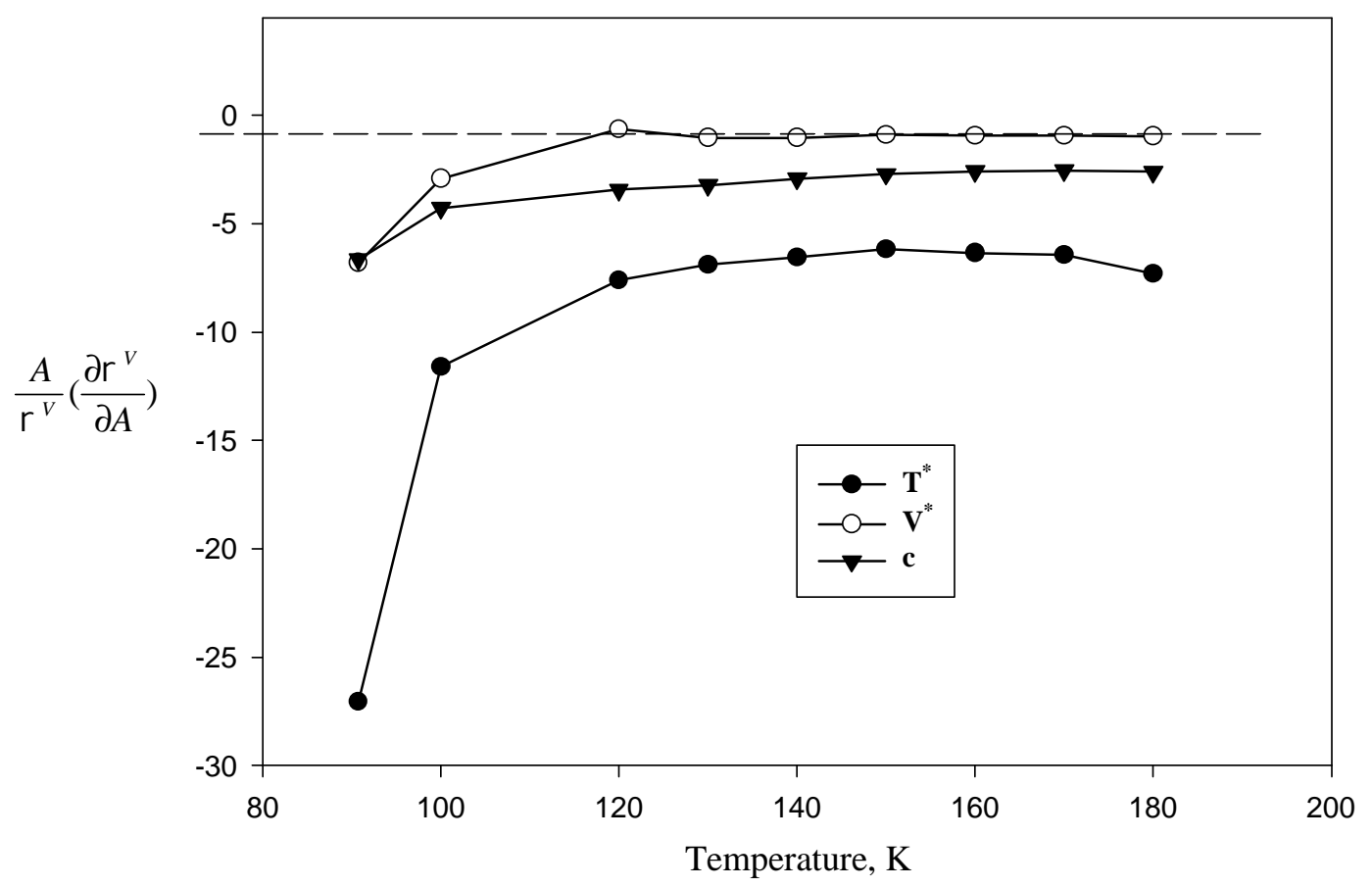

Figure 5. Effect of Temperature on Vapor Density Sensitivity for Saturated Methane. 


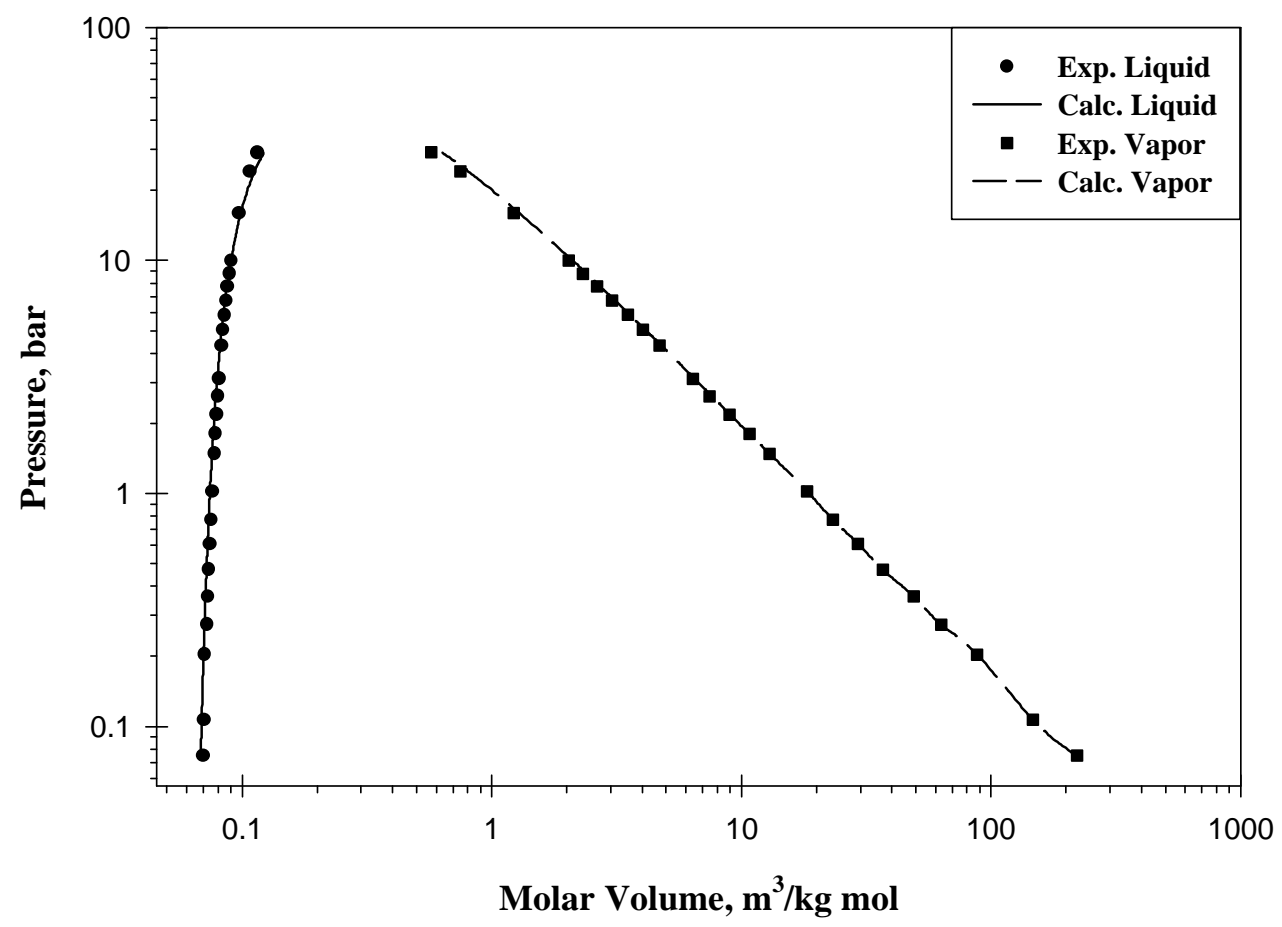

Figure 6. Experimental and Calculated Vapor Pressures and Phase Molar Volumes for Propane. 


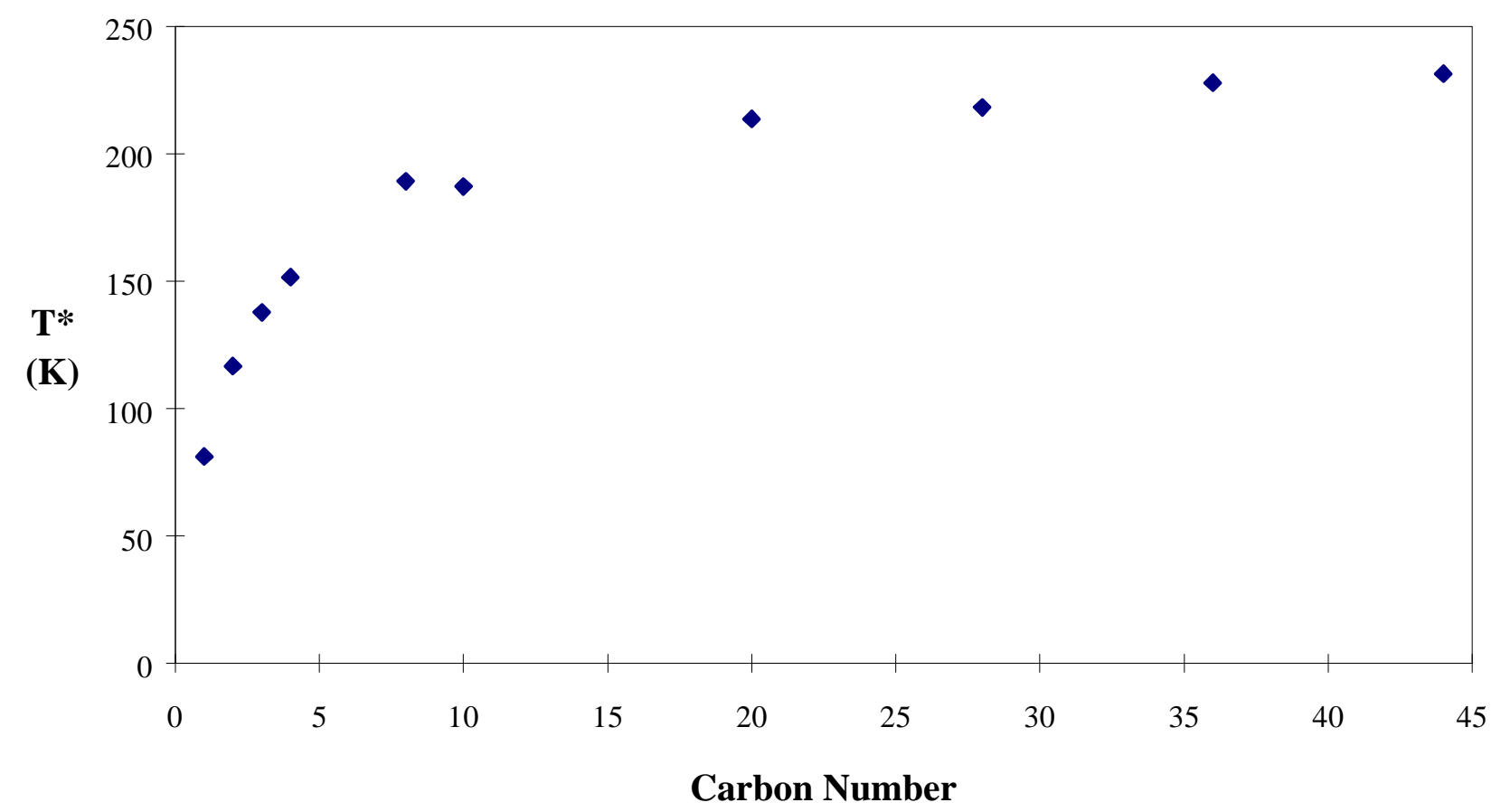

Figure 7. Characteristic Temperature, $\mathrm{T}^{*}$, of Normal Paraffins. 


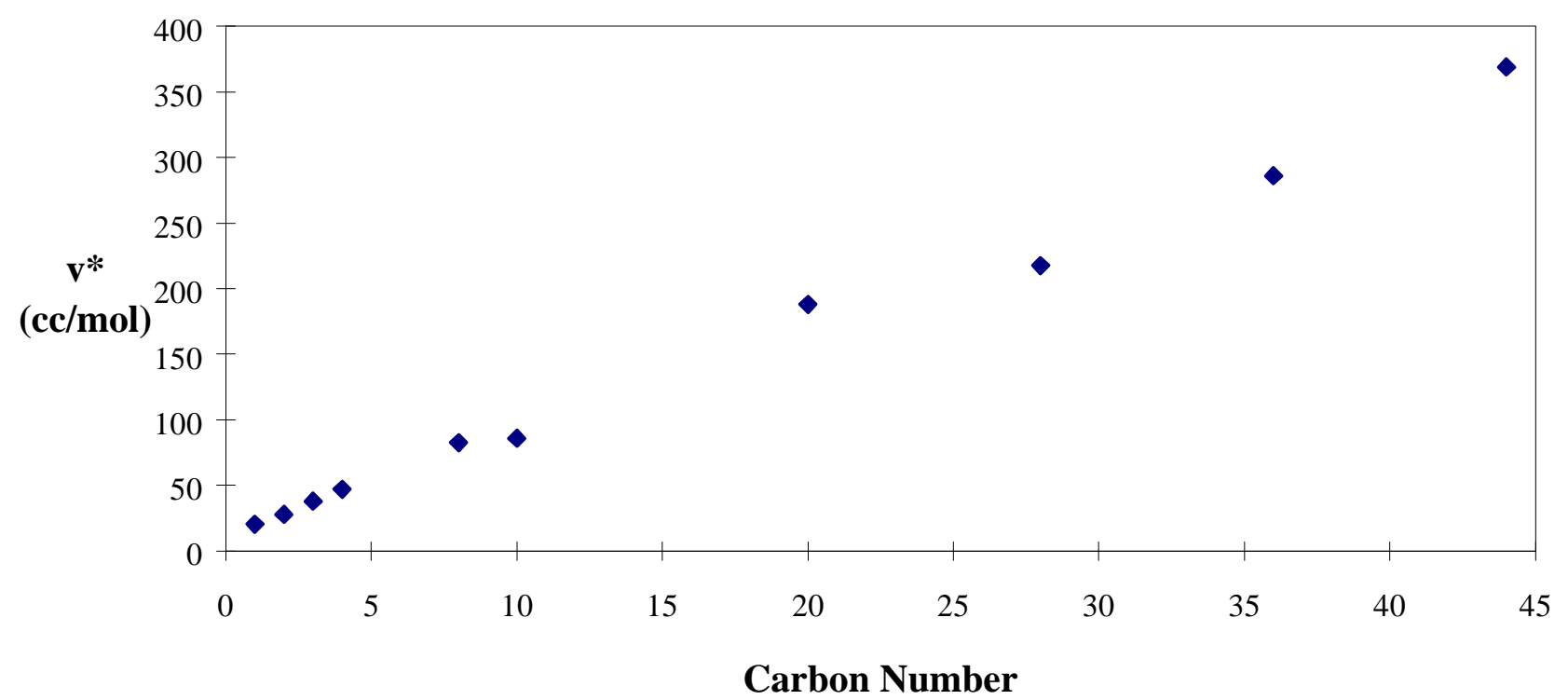

Figure 8. Characteristic Volume, $\mathrm{v}^{*}$, of Normal Paraffins. 


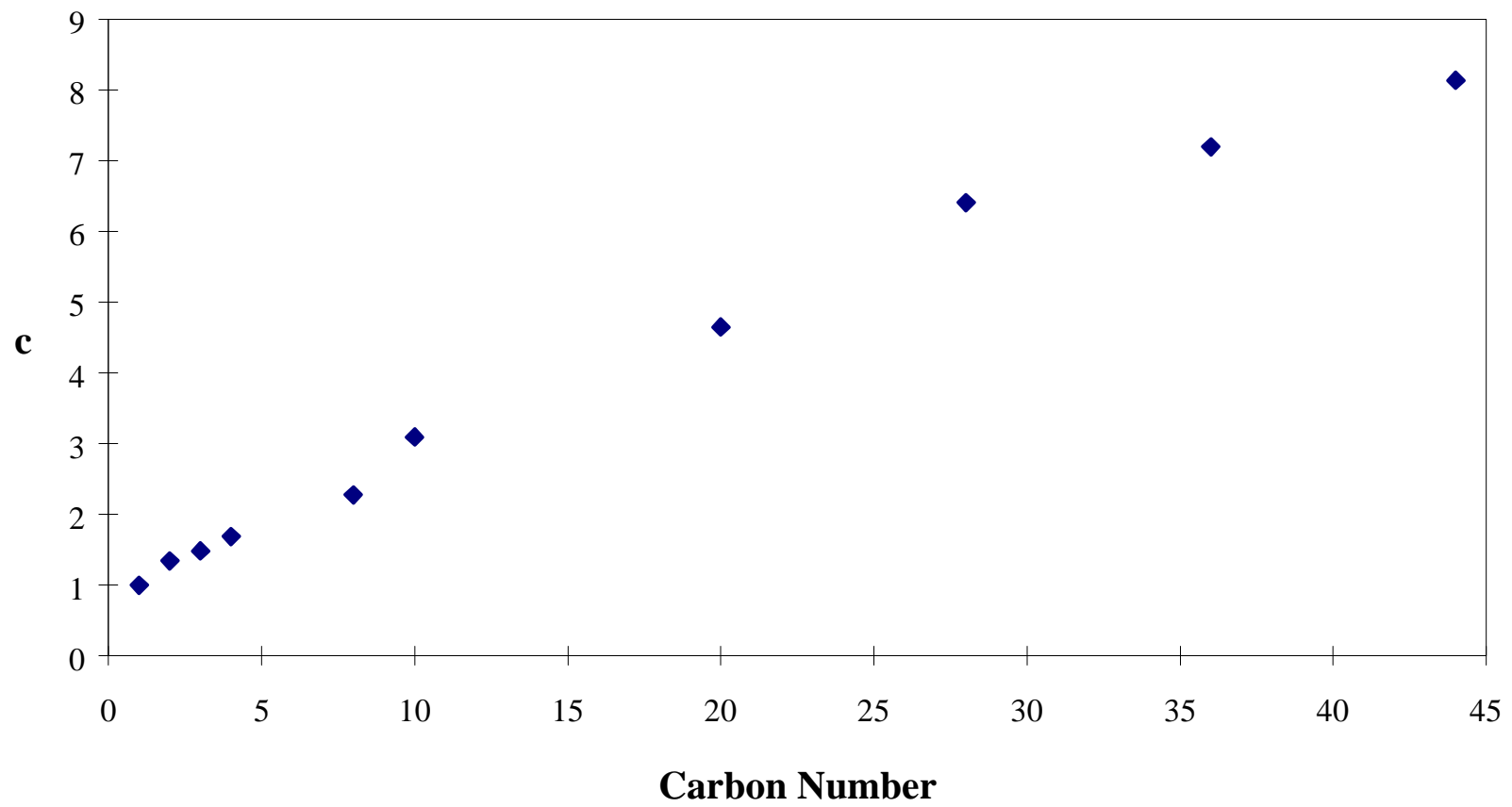

Figure 9. Degree of Freedom Parameter, c, of Normal Paraffins. 
